\title{
Long-term repetition priming with symmetrical polygons and words
}

\author{
ZOE KERSTEEN-TUCKER \\ University of California, Berkeley, California \\ and VA Medical Center, Martinez, California
}

\begin{abstract}
In two different tasks, subjects were asked to make lexical decisions (word or nonword) and symmetry judgments (symmetrical or nonsymmetrical) about two-dimensional polygons. In both tasks, every stimulus was repeated at one of four lags $(0,1,4$, or 8 items interposed between the first and second stimulus presentations). This paradigm, known as repetition priming, revealed comparable short-term priming $(\operatorname{Lag} 0)$ and long-term priming (Lags 1,4 , and 8 ) both for symmetrical polygons and for words. A shorter term component (Lags 0 and 1) of priming was observed for nonwords, and only very short-term priming ( Lag 0 ) was observed for nonsymmetrical polygons. These results indicate that response facilitation accruing from repeated exposure can be observed for stimuli that have no preexisting memory representations and suggest that perceptual factors contribute to repetition-priming effects.
\end{abstract}

Presentation of a stimulus facilitates subsequent identification of that stimulus. Known both as the repetition effect and as repetition priming, this phenomenon has been studied in tasks involving word identification (Feustal, Shiffrin, \& Salasoo, 1983; Salasoo, Shiffrin, \& Feustal, 1985), word-stem completion (Graf, Shimamura, \& Squire, 1985), reading transformed text (Kolers, 1976), picture naming (Mitchell, 1989), and lexical decision (Bentin \& Moscovitch, 1988; Scarborough, Cortese, \& Scarborough, 1977). Recent investigations using the lexical decision paradigm have demonstrated that the response facilitation accrued from repeated exposure has two components (Bentin \& Moscovitch, 1988; Forster \& Davis, 1984; Ratcliff, Hockley, \& McKoon, 1985; Scarborough et al., 1977). A short-term component is observed when two stimuli are presented sequentially; a lesser, but still significant, degree of facilitation is observed when different stimuli are interposed between the first and second presentation (long-term component).

Several hypotheses have been developed to account for the components of the repetition effect. The traditional interpretation is that the initial presentation of a stimulus temporarily activates its lexical representation in semantic memory. The notion of activation here corresponds to that used in theoretical models of cognition (e.g., An-

This research was conducted in partial fulfillment of the requirements for a PhD at the University of Califomia, Berkeley. The work was supported by NIH Grant NS 21135 and by the Veterans Administration Research Service. I would like to thank James I. Chumbley, Curtis Hardyck, Robert T. Knight, Art Shimamura, and three anonymous reviewers for their insightful comments on this manuscript. Thanks also go to Xiao Lan for technical support. Correspondence should be addressed to Zoe Kersteen-Tucker, Neuropsychology Laboratory, Room 4331, School of Education, University of California, Berkeley, CA 94720. E-mail: kersteen@garret.berkeley.edu. derson, 1976, 1983). This process is characterized by rapid activation of a node in semantic memory, with activation decaying rapidly, thereby allowing the system to perform other tasks without being overwhelmed by activation left over from earlier processes. As a result of recent activation, it is hypothesized that the lexical representation remains in a state of increased accessibility for a short period of time (Clarke \& Morton, 1983; Morton, 1979), thereby facilitating response after the second exposure.

While the activation hypothesis has been used to account for both the short-term (Forster \& Davis, 1984; Humphreys, Besner, \& Quinlan, 1988; Ratcliff et al., 1985 ) and long-term (Clarke \& Morton, 1983; Morton, 1979) effects of repetition, it has become an increasingly difficult theoretical position to maintain. Evidence in conflict with an "activation" or "threshold lowering" explanation of the short-term repetition priming effect (when two stimuli are presented sequentially) is derived from studies utilizing stimuli that have no existing memorial representation. Several investigators report short-term repetition effects for nonwords (Bentin \& Moscovitch, 1988; Feustal et al., 1983; Salasoo et al., 1985; Scarborough et al., 1977). In these studies, short-term facilitation of the same magnitude has been obtained for both words and nonwords. Unlike the long-term repetition effect observed for words, response facilitation resulting from repeated exposure is observed only when identical nonwords are presented sequentially. Bentin and Moscovitch (1988) also obtained short-term repetition effects with unfamiliar faces. In this investigation, the effects of repetition were assessed for words and nonwords in a lexical decision task and in a face-perception task in which subjects were shown unfamiliar faces and nonfaces and were required to discriminate betwen the two. Repe- 
tition effects were examined at lags of 0,4 , and 15 items (items intervening between first and second presentation). Significant short-term repetition effects (Lag 0 ) were obtained for all four stimulus types. Long-term response facilitation (Lags 4 and 15) was observed only for words.

With respect to the long-term component, repetition effects have been sustained even when many stimuli intervene between the first and second exposure in a given experimental session (Mitchell, 1989), across days (Squire, Shimamura, \& Graf, 1987), and even across years (Kolers, 1976; Salasoo et al., 1985). Results of this type are problematic for the activation model, in that if the effects of repetition persist over long periods of time, thresholds of all nodes in semantic memory should eventually be permanently lowered. Effects of repetition are also sensitive to changes in the modality of first and second presentation (Clarke \& Morton, 1983; Jacoby, 1983). Jacoby (1983), for example, has shown that auditory presentation of a stimulus does not enhance subsequent visual perceptual identification. If a node in semantic memory becomes activated as a result of prior exposure, changes in modality should have minimal impact on response facilitation. Finally, several studies demonstrate that repetition effects are orthogonal to the effects of semantic priming (Den Heyer, Goring, \& Dannenbring, 1985; Wilding, 1986), a result not predicted if both effects result from the activation of a common representation in semantic memory.

These results indicate that it is no longer possible to easily explain response facilitation accruing from repeated presentation to the activation of an existing representation in lexical-semantic memory. Alternatively, it has been suggested that the most parsimonious interpretation of repetition effects at both short and long lags is that they result from the modification or acquisition of memory representations by recent experience (Forster \& Davis, 1984; Humphreys et al., 1988; Jacoby, 1983; Jacoby \& Hayman, 1987). At Lag 0, perceptual operations leading to recognition of the repeated item are faster and more efficient. Recognition, in this instance, permits response without the subject's having to recapitulate the operations that led to the first decision (Bentin \& Moscovitch, 1988).

At longer repetition intervals, episodic factors attributed to the conscious processing of the first stimulus presentation are thought to shorten response latency following the second exposure. As evidence for the episodic contribution to repetition effects, Forster and Davis (1984) report that masking the first presentation of a lexical decision stimulus to a subthreshold level still results in a significant degree of response facilitation for words in an immediate-repeat condition. In contrast, masking eliminated the long-term effect for words and the short-term effect for nonwords. Using a word-identification paradigm in which the first presentation of a stimulus was again masked, Humphreys et al. (1988) also obtained reliable immediate-repetition effects that did not extend beyond the sequential pairing of first and second stimulus exposure. Forster and Davis (1984) and Humphreys et al.
(1988) similarly conclude that long-term repetition effects are observed only if there is conscious processing of the first stimulus presentation. Conscious processes are thought to mediate the formation of an episodic record of the stimulus, which facilitates processing on subsequent presentations.

However, the pure episodic interpretation does not account for the observation that long-term repetition priming effects have been obtained for words only. If repetition effects are not contingent on the existence of a lexical-semantic representation but are solely related to the formation of an explicit episodic record of the first stimulus presentation, then long-term repetition effects should not be selective for words. Thus, the reported absence of long-term repetition effects for nonwords, faces, and nonfaces is problematic for the episodic hypothesis in its current form.

Several alternative explanations could account for the paradoxical findings. The first possibility is that long-term repetition effects may be maintained for nonlexical stimuli under more favorable experimental conditions. It is possible that the nonlexical stimuli used in previous studies were too visually complex or uncodable to support the creation of a durable episodic trace. According to this hypothesis, use of a nonverbal stimulus set that minimizes visual processing demands should elicit long-term repetition effects. Some evidence for this hypothesis comes from Salasoo et al. (1985), who have shown that longterm repetition effects can be obtained for nonwords if they are shown to subjects several times. Salasoo et al. conclude that when a memory trace is formed for items that have no lexical representation, it takes several exposures to the stimulus. They ascribe this accretion of a trace over repeated exposures to a process called codifcation. Accordingly, the maintenance of long-term repetition effects is contingent not on the existence of a lexicalsemantic representation, but rather on the creation of a reliable code.

The present study was designed to assess whether a lexical representation is a necessary condition for the attainment of long-term priming. A task involving the discrimination of symmetry/nonsymmetry in simple twodimensional polygons was developed and utilized in conjunction with a lexical decision task. Symmetry discrimination was chosen as a complement to lexical decision because symmetry is a salient perceptual feature that appears to be extracted early in the course of visual information processing (Ramachandran, 1988) and the symmetry-detection mechanism appears to be extremely versatile and efficient (Barlow \& Reeves, 1979; Bruce \& Morgan, 1975). In both tasks, the effects of repetition were assessed at Lags 0, 1, 4, and 8. It was hypothesized that directing attention to a salient perceptual feature, such as symmetry, would create a more favorable experimental environment for the creation of a memory trace that could support long-term repetition effects. Hence, shortand long-term repetition effects would be expected in both the lexical decision and the symmetry-judgment task. If, 
on the other hand, long-term repetition effects are linked to the existence of a lexical-semantic representation, longterm repetition effects should be observed only for words.

\section{METHOD}

\section{Subjects}

Five women and 9 men were recruited from the VA Medical Center volunteer service to serve as subjects. Together, their mean age and years of education were 56 years (range of 21 to 74 years) and 13 years (range of 8 to 18 years), respectively. All subjects were right-handed, as assessed by a modified Edinborough Handedness Inventory, had normal or corrected-to-normal vision, and spoke English as a first language. Each subject was paid a total of $\$ 40$ for his/her participation in this and one other experiment.

\section{Stimuli and Apparatus}

All stimuli were displayed in white on a black background on an IBM personal computer color video monitor. This monitor, outfitted with an extended graphics adapter (EGA), was placed atop an IBM/AT personal computer which controlled stimulus presentation and timing and recorded the subjects' responses. Two joysticks, interfaced to the IBM PC via the installation of a game port card, were used to record the subjects' responses.

Lexical decision stimuli. Stimulus items consisted of 80 fiveletter words and an equivalent number of five-letter nonwords (see Appendix). The word stimuli, taken from Toglia and Battig's (1978) compendium of word norms, were all rated high on dimensions of imageability, familiarity, and concreteness. Nonword stimuli were constructed by taking 80 additional words from Toglia and Battig (comparable in familiarity, concreteness, and imageability) and altering one letter to create a pronounceable, orthographically legal nonsense string. Each letter position was altered equally often in creating the nonword corpus, thereby ensuring that initial, medial, and final letters were equally important for accurate word/nonword discriminations. These stimuli were horizontally presented in uppercase, subtending $4.19^{\circ}$ of horizontal and $0.90^{\circ}$ of vertical visual angle. The third letter of each stimulus was positioned in the center of the display device.

Symmetry-judgment stimuli. Stimuli for the symmetry judgment consisted of 80 symmetrical and 80 nonsymmetrical twodimensional polygons (see Figure 1).

Both polygon types were eight-sided, on the average. The shapes varied in size from $5^{\circ}$ to $1.5^{\circ}$ of visual angle and were presented within a radius of $4.0^{\circ}$ from the center of the display device. The axis of symmetry was unconstrained for the symmetrical shapes.

\section{Procedure}

Each subject was tested in both the lexical decision and the symmetry-judgment task. In the lexical decision task, the 80 words and nonwords were presented in two blocks of 160 trials each (40 words and 40 nonwords, each repeated once). Similarly, the 160 polygons were presented in two blocks of 40 symmetrical and 40 nonsymmetrical shapes, each repeated once. In each group (words, nonwords, symmetrical shapes, and nonsymmetrical shapes), an equal number of stimuli were randomly assigned to each of four lag conditions, with special care taken to match items at each lag: Lag 0 (the second presentation immediately followed the first), Lag 1 (one stimulus was interposed between the first and second presentation), Lag 4 (four stimuli separated the two presentations), and Lag 8 (eight stimuli intervened between the first and second presentations).

The experiment took place in a dimly lit, sound-attenuated room. The subjects were seated in front of the video monitor with their arms resting on a table in front of them. Viewing distance was $50 \mathrm{~cm}$ for the lexical decision task and $114 \mathrm{~cm}$ for the symmetry-judgment task. These distances were chosen so that the average visual angle
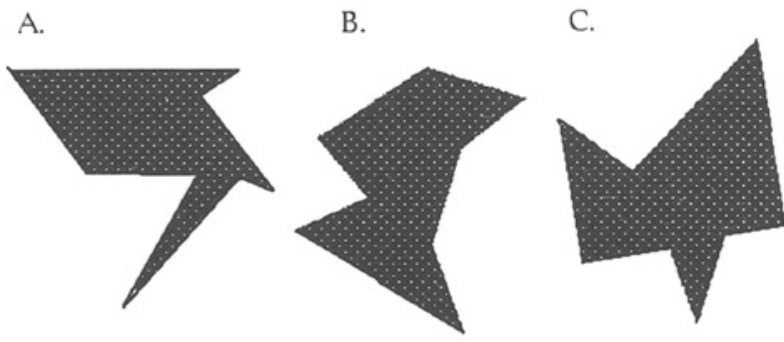

\section{SYMMETRICAL POLYGONS}

D.
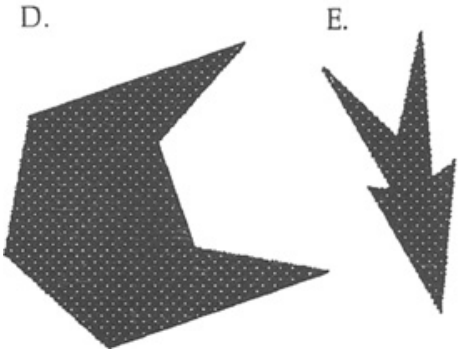

Figure 1. Examples of the nonsymmetrical and symmetrical polygons used in the symmetry-judgment task.

subtended by the polygons was comparable to that subtended by the letter strings. A joystick was positioned in each hand, so the button on top of the joystick could be comfortably depressed by the thumb. The subjects were instructed to press one of the two joystick buttons according to whether the stimulus was or was not a word (in the lexical decision task) or according to whether the stimulus was or was not symmetrical (in the symmetry-judgment task). Half of the subjects responded word/symmetrical with the right hand and nonword/nonsymmetrical with the left, and half of the subjects responded in the opposite pattern. Each subject saw all four blocks of trials (two lexical decision blocks and two symmetry-judgment blocks); the order in which the four blocks were presented was randomized for each subject.

Prior to both the first block of lexical decision trials and the first block of symmetry-judgment trials, the subjects were given practice trials with 20 stimuli that were not included in the experimental blocks. For lexical decision, the subjects were told that they would see a series of letter strings appearing on the screen in front of them and that their task was to decide whether these strings did or did not spell English words. For the symmetry-judgment task, the subjects were told that they would see a series of shapes appearing on the screen and that they were to decide whether or not these shapes were symmetrical. A brief explanation of the concept of symmetry was given using paper and pencil prior to the onset of the practice trials. In both the practice and the experimental trials, the subjects were instructed to respond to each stimulus and to give equal emphasis to speed and accuracy. For both types of practice trials, the subjecs were given unlimited viewing time and feedback on their accuracy after each trial. No feedback was provided during the experimental trials.

Following the practice trials, the test stimuli were administered. Each stimulus was presented for $150 \mathrm{msec}$, followed by the appearance of a fixation point located $0.5^{\circ}$ of visual angle above the center point of the display. A stimulus onset asynchrony of $2 \mathrm{sec}$ was used for both the lexical decision and the symmetry-judgment task. Both reaction time ( $\mathrm{RT}$ ), as measured in milliseconds from stimulus offset to response, and response accuracy were collected as dependent 
Table 1

Mean Proportion of Correct Classifications, Mean First-Presentation RTs (in milliseconds), and Standard Error of the Means for Words, Nonwords, Symmetrical Polygons, and Nonsymmetrical Polygons

\begin{tabular}{lccccc}
\hline & \multicolumn{3}{c}{$\begin{array}{c}\text { Proportion } \\
\text { Correct }\end{array}$} & & \multicolumn{2}{c}{ First RTs } \\
\cline { 2 - 3 } \cline { 6 - 7 } \multicolumn{1}{c}{ Stimulus Type } & $M$ & $S E M$ & & $M$ & $S E M$ \\
\hline Word & 0.96 & 0.01 & & 439.00 & 22.30 \\
Nonword & 0.92 & 0.03 & & 495.00 & 33.06 \\
Symmetrical Polygon & 0.88 & 0.02 & & 575.00 & 20.10 \\
Nonsymmetrical Polygon & 0.87 & 0.03 & & 607.00 & 33.89 \\
\hline
\end{tabular}

variables. RTs and proportion of errors were averaged separately for each stimulus group. A 5-min break was given between each block of trials. The subjects were not informed of the purpose of the experiment until the end of the experimental session, at which point they were debriefed and shown their results.

\section{RESULTS}

For each subject, median RTs and errors were extracted across stimuli at each lag for words, nonwords, symmetrical polygons, and nonsymmetrical polygons. Only RTs for correctly classified stimuli were included in the RT analyses; only RTs for stimuli classified correctly on both presentations were used in the analysis of the effects of repetition. Prior to examining the effects of stimulus repetition, preliminary analyses were conducted to characterize task differences in accuracy and overall RT. To determine whether signal-detection analyses were warranted, decision type $($ signal $=$ word, symmetrical polygon; noise = nonword, nonsymmetrical) was used as an independent variable in the first two analyses.

\section{Accuracy Analyses}

An analysis of response accuracy with the proportion of correct responses as the dependent variable was conducted using a within-subjects $2 \times 2$ analysis of variance (ANOVA). The independent variables were task (lexical decision and symmetry judgment) and decision type. Only a significant main effect of task was obtained $[F(1,13)=$ $\left.6.69, M S_{\mathrm{e}}=.008, p<.02\right]$, indicating that the subjects performed more accurately in the lexical decision task than in the symmetry-judgment task (see Table 1). Since neither a main effect of decision type nor a task $\times$ decision type interaction was obtained, signal-detection analyses were not conducted.

\section{Reaction-Time Analyses}

To assess whether there were task or decision-type differences in overall RT, a within-subjects, two-way ANOVA was performed. For this analysis, only median RTs for the initial stimulus classification were used for each subject in each of the four conditions (see Table 1). Results yielded significant main effects both for task $\left[F(1,13)=48.65, M S_{\mathrm{e}}=4,473.37, p<.00001\right]$ and for stimulus type $\left[F(1,13)=5.44, M S_{\mathrm{e}}=5,009.62\right.$, $p<.05]$. The subjects were quicker to respond in the lexical decision task (average RT for lexical decision = $467 \mathrm{msec}$; average RT for symmetry judgment = $592 \mathrm{msec}$ ) and were faster at classifying words and symmetrical polygons than they were at classifying nonwords or nonsymmetrical polygons.

\section{Effects of Stimulus Repetition}

Several analyses were conducted to assess the effects of repetition. First, median facilitation scores were calculated for each subject in each stimulus condition (word, nonword, symmetrical polygon, and nonsymmetrical polygon) and at each lag $(0,1,4$, and 8$)$. These scores were obtained by subtracting the RT for the second stimulus presentation from the RT for the first stimulus presentation for every stimulus item that was classified correctly after both presentations. Median values were then obtained for each subject in each of the 16 conditions. The resulting facilitation scores averaged across subjects and standard errors of the mean (SEM) are found in Table 2 and are depicted graphically in Figure 2.

To assess whether the facilitation observed at each lag for each stimulus type differed from zero, a series of nondirectional $t$ tests were performed $(p<.05)$. As shown in Table 2, significant priming was observed at each lag for words and symmetrical polygons. For nonwords, priming was significant at Lags 0 and 1 ; for nonsymmetrical polygons, a reliable degree of priming was observed only at Lag 0 .

To determine whether there were differences in facilitation as a function of lag, separate single-factor, repeated measures ANOVAs were performed on the facilitation scores for each of the four stimulus types. $\operatorname{Lag}(0,1,4$, and 8) was treated as the repeated measure. Results indicate that the effects of lag were significant for words $\left[F(3,39)=4.859, M S_{\mathrm{e}}=1,278.47, p<.005\right]$, nonwords $\left[F(3,39)=18.5, M S_{\mathrm{e}}=4,172.83, p<.0001\right]$, and symmetrical polygons $\left[F(3,39)=2.965, M S_{e}=\right.$

Table 2

Summary of the Mean Facilitation Scores and Standard Error of the Means at Each Lag for Words, Nonwords, Symmetrical Polygons, and Nonsymmetrical Polygons

\begin{tabular}{|c|c|c|c|c|c|c|c|c|}
\hline \multirow[b]{2}{*}{ Stimulus Type } & \multicolumn{2}{|c|}{ Lag 0} & \multicolumn{2}{|c|}{ Lag 1} & \multicolumn{2}{|c|}{ Lag 4} & \multicolumn{2}{|c|}{ Lag 8} \\
\hline & $M$ & $S E M$ & $M$ & $S E M$ & $M$ & $S E M$ & $M$ & $S E M$ \\
\hline Word & $93.0^{*}$ & 10.9 & $61.9^{*}$ & 9.6 & $48.5^{*}$ & 6.6 & $65.4^{*}$ & 11.7 \\
\hline Nonword & $100.57^{*}$ & 15.0 & $40.21^{*}$ & 8.6 & -5.1 & 9.1 & -2.8 & 12.2 \\
\hline Symmetrical Polygon & $94.5^{*}$ & 8.0 & $65.07^{*}$ & 17.6 & $50.28^{*}$ & 9.4 & $53.5^{*}$ & 12.0 \\
\hline Nonsymmetrical Polygon & $24.71 *$ & 9.9 & 29.1 & 14.7 & 10.9 & 9.4 & 12.3 & 10.5 \\
\hline
\end{tabular}

$*_{p}<.05$, nondirectional. 


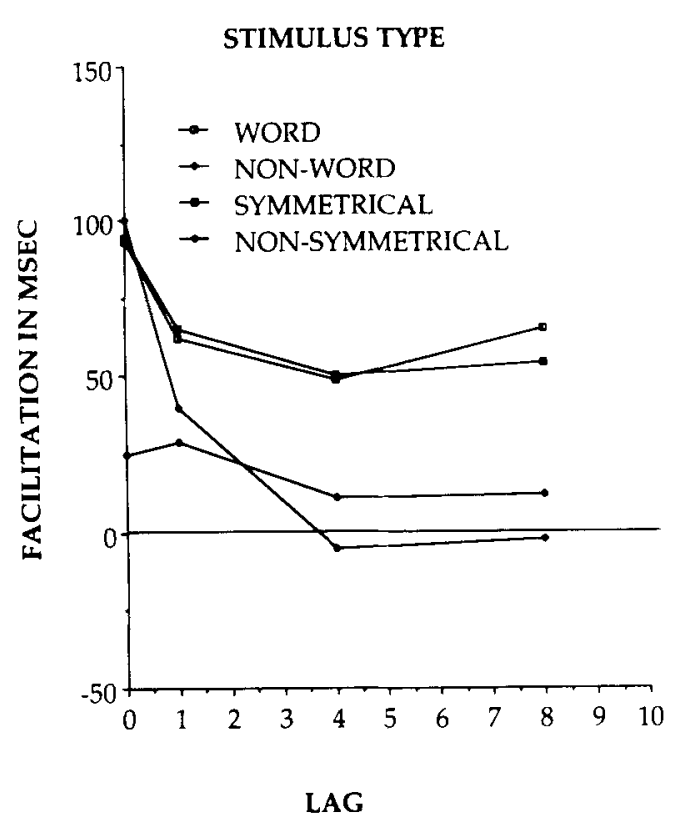

Figure 2. Mean facilitation scores (first presentation reaction time minus reaction time for second presentation) plotted across Lags $0,1,4$, and 8 for words, nonwords, symmetrical polygons, and nonsymmetrical polygons.

$2,182.81, p<.04$ ] No significant lag effects were obtained for nonsymmetrical polygons.

Subsequent comparisons of response facilitation at the individual lags were conducted for words, nonwords, and symmetrical polygons using Fisher's protected least significant difference (PLSD) method (Milliken \& Johnson, 1984). Response facilitation for words was significantly greater at Lag 0 than at Lags 1,4 , and $8(p<.05$ for each comparison, $P L S D=24.2$ ), which did not differ. For nonwords, facilitation at Lag 0 was also greater than at Lags 1,4 , and $8(p<.05, P L S D=32.9)$. In addition, facilitation at Lag 1 was greater than that at Lags 4 and $8(p<.05)$. Finally, the facilitation observed at Lag 0 for symmetrical polygons was significantly greater than that for Lags 4 and $8(p<.05, P L S D=33.5)$. The lack of a significant difference between Lag 0 and Lag 1 for symmetrical polygons may be attributed to the elevated standard error associated with the symmetrical shapes at Lag 1 (see Table 2).

\section{DISCUSSION}

Results of the current investigation support the hypothesis that perceptual, rather than lexical, characteristics of the stimulus dictate whether repetition effects will be observed. Comparable short- and long-term repetition functions were observed for both words and symmetrical polygons. Support for the component approach (Bentin \& Moscovitch, 1988) was also obtained. A significant shortterm repetition priming component was shown to differ from a lesser, but still significant, long-term repetition effect for words and symmetrical polygons. However, stimulus type was shown to moderate the two components of repetition priming. Only very short-term priming was observed for nonsymmetrical polygons; only short-term priming was observed for nonwords.

The short-term effect of repetition is likely due to explicit memory processes related to recognition of the stimulus. When an identical stimulus is presented sequentially, recognition following the second presentation eliminates the need to duplicate the initial decision process, thereby resulting in a shorter response latency. When one or more different stimuli intervene between first and second exposure, this source of response facilitation is not accessible.

At longer lags, it has been hypothesized that episodic factors (Bentin \& Moscovitch, 1988; Forster \& Davis, 1984; Humphreys et al., 1988), possibly related to a consciously accessible record of the first presentation, govern the effects of repetition. In their discussion of the absence of long-term repetition effects for facial stimuli, Bentin and Moscovitch (1988) stress the importance of the preexperimental history of repeated items. They assert that a memory record of the type hypothesized to exist for words is important because its existence allows for a deeper and more elaborate encoding of the item at its first presentation. Hence, exposure to familiar and meaningful items supports the existence of a more durable episodic trace. While this account avoids the construct of lexical activation, it ascribes special status, in terms of the maintenance of repetition effects, to items with an existing lexical-semantic representation. In contrast, results of the present study indicate that priming can occur for stimuli without a preexperimental history. It appears that perceptual characteristics of the stimuli determine whether facilitative effects of repetition will be sustained in time. The fact that identical short- and long-term repetition effects were obtained for words and symmetrical polygons provides support for this hypothesis. A single exposure to an unfamiliar, nonlexical stimulus is enough to support the acquisition of a memory representation that can produce long-term response facilitation.

However, the foregoing discussion provides no explanation for the absence of long-term repetition effects for nonwords and nonsymmetrical polygons. Goldmeier (1982) has proposed a trace theory of memory in which visual, as well as verbal, traces are regarded as the end product of drastic data reduction. According to Goldmeier, a memory trace is laid down differently for different types of stimulus configurations. It is hypothesized that singular patterns (verbal or nonverbal) are regular patterns which form a strong whole and are easiest to recognize and remember. A near-singular pattern is perceived or encoded as a variant of the good or typical one. Finally, a nonsingular stimulus is difficult to perceive and code in exact detail and, hence, is difficult to remember. Singularity, in Goldmeier's theoretical frame of reference, is akin to the Gestalt notion of Prägnanz. While it is beyond the scope of this paper to detail Goldmeier's theory, his approach is relevant. Symmetrical polygons are, 
by their nature, singular; they are regular and selfconsistent. Because they are visually redundant, they more easily undergo the data-reduction processes that are thought to occur in the formation of a memory trace. Thus, we would expect that because of their special perceptual qualities, symmetrical polygons, like words, would support the encoding of a durable memory trace and, hence, long-term repetition effects.

Nonwords, of the type used in this study, fall into the near-singular perceptual category. They are pronounceable, orthographically correct, and (except for the lack of meaning) could be words. It has been suggested (Balota \& Chumbley, 1984) that nonwords can be characterized by their location on a gradient of "wordness." Pronounceable, orthographically correct nonwords (e.g., NEMON) are perceived as more "wordlike" than those that are nonpronounceable and do not follow the rules of English orthography (e.g., TVRLs). If we assume that lexicality, like symmetry, forms a strong perceptual category, we may predict that more wordlike nonwords are more codable than those at the opposite end of the wordness spectrum. Wordlike nonwords obey certain rules that allow them to be perceived, encoded, and remembered more accurately than do objects or letter strings that have no internal constraints. Hence, the nonwords used in this study, by virtue of their conformity to the orthographic and phonotactic rules of the English language, are capable of producing a short-term visual memory trace, which is manifest in the observed short-term repetition effect. An interesting test of this hypothesis would be to use nonwords from the opposite end of the wordness spectrum. One would predict that these stimuli would support very short-term, but not long-term, repetition effects.

Nonsymmetrical polygons represent the nonsingular end of the perceptual spectrum. They have no internal consistency or goodness of form; in short, they are perceptually chaotic and resist codification. For this reason, the repetition of nonsymmetrical polygons will not sustain long-term response facilitation and yields only a very short-term priming effect.

From the present pattern of results, it is hypothesized that the process that subserves long-term repetition effects is guided by rules about configural goodness. Stimuli that conform to these rules are encoded in a way that produces a more durable trace, which in turn supports long-term repetition,effects. A recent study by Schacter, Cooper, and Delaney (1990), who used a rather different nonverbal priming paradigm, has yielded a pattern of results that is quite relevant. Schacter et al. created a series of twodimensional drawings of novel, unfamiliar threedimensional objects. Half of the drawings were structurally "possible"; the other half were drawn with edge, contour, or surface violations that rendered it impossible for them to exist in the three-dimensional world. Following an initial study interval in which subjects were exposed to both types of objects, priming was assessed in an object-decision task in which subjects were asked to judge whether or not each of a series of objects was struc- turally possible. Half of the objects had been studied earlier, and half were new. The relevant finding is that significant priming was observed only for the structurally possible objects that had been previously studied. No priming was observed for the structurally impossible objects.

Tulving and Schacter (1990) postulate that priming of the type indexed by the object-decision task is a manifestation of the perceptual representation system-a system thought to be independent of other memory systems. It is suggested that priming of object perception depends upon the encoding of and subsequent access to a coherent structural description, and the perceptual representation system performs these operations (Schacter et al., 1990). Since impossible objects lack structural coherence, they are not encoded by the perceptual representation system. Resemblance of the symmetry-decision results to those of Schacter et al. suggests both that the long-term priming observed in the present study may reflect the operation of the perceptual representation system and that this system uses stimulus-decomposition rules that are based on configural goodness. Interestingly, Schacter et al. have shown that the priming of objects in their structural decision task is implicit and does not involve conscious recollection of any previous experiences. This notion appears to conflict theoretically with the hypothesis that the long-term effects of repetition are episodic.

Clearly, an answer to the question of whether shortand long-term repetition effects index separate memory systems or whether both components are episodic is imperative. In addition, the influence of configural goodness and structure on repetition priming requires further investigation. It appears that mental representations of visual objects exist on several distinct levels, ranging from structural to semantic. Repetition-priming paradigms appear to tap rule-based, structural representations. Hence, it seems most appropriate to interpret these effects from a broader perspective of visual perception.

\section{REFERENCES}

ANDERSON, J. (1976). Language, memory and thought. Hillsdale, NJ: Erlbaum.

ANDERSON, J. (1983). The architecture of cognition. Cambridge, MA: Harvard University Press.

Balota, D., Chumbley, J. (1984). Are lexical decisions a good measure of lexical access? The role of word frequency in the neglected decision stage. Joumal of Experimental Psychology: Human Perception \& Performance, 10, 340-357.

Barlow, H. B., ReEves, B. C. (1979). The versatility and absolute efficiency of detecting mirror symmetry in random dot displays. $V_{i-}$ sion Research, 19, 783-793.

Bentin, S., \& Moscovitch, M. (1988). The time course of repetition effects for words and unfamiliar faces. Journal of Experimental Psychology: General, 117, 148-160.

Bruce, V. G., \& MORGaN, M. J. (1975). Violations of symmetry and repetition in visual patterns. Perception, 4, 239-249.

Clarke, R., \& Morton, J. (1983). Cross modality facilitation in tachistoscopic word recognition. Quarterly Journal of Experimental Psychology, 35A, 79-96.

Den Heyer, K., Goring, A., \& Dannenbring, G. (1985). Semantic 
priming and word repetition: The two effects are additive. Joumal of Memory \& Language, 24, 699-716.

Feustal, T., Shiffrin, R., \& Salasoo, A. (1983). Episodic and lexical contributions to the repetition effect in word identification. Journal of Experimental Psychology: General, 112, 309-346.

Forster, K., \& DAvis, C. (1984). Repetition priming and frequency attenuation in lexical access. Joumal of Experimental Psychology: Leaming, Memory \& Cognition, 10, 684-698.

GOLDMEIER, E. (1982). The memory trace: Its formation and its fate. Hillsdale, NJ: Erlbaum.

Graf, P., Shimamura, A., \& Squire, L. (1985). Priming across modalities and priming across category levels: Extending the domain of preserved function in amnesia. Joumal of Experimental Psychology: Learning, Memory \& Cognition, 11, 386-396.

Humphreys, G., Besner, D., \& Quinlan, P. (1988). Event perception and the word repetition effect. Journal of Experimental Psychology: General, 117, 51-67.

JACOBY, L. (1983). Perceptual enhancement: Persistent effects of an experience. Joumal of Experimental Psychology: Learning, Memory \& Cognition, 9, 21-38.

Jacoby, L., \& Hayman, G. (1987). Specific visual transfer in word identification. Joumal of Experimental Psychology: Leaming, Memory \& Cognition, 13, 456-463.

KoLERS, P. A. (1976). Reading a year later. Joumal of Experimental Psychology: Human Leaming \& Memory, 2, 554-565.

Milliken, J., \& JohNson, D. (1984). Analysis of messy data. Belmont, CA: Lifetime Leaming Publications.

Mrtchell, D. (1989). How many memory systems? Evidence from aging. Joumal of Experimental Psychology: Leaming, Memory \& Cognition, 18, 31-49.

MorTon, J. (1979). Facilitation in word recognition: Experiments causing change in the logogen model. In P. A. Kolers, M. E. Wrolstad, \& H. Bouma (Eds.), Processing of visible language 1 (pp. 259-268), New York: Plenum.

Ramachandran, V. (1988). Shape from shading. Scientific American, 259(2), 76-83.

RATClif, R., Hockley, W., McKoon, G. (1985). Components of activation: Repetition and priming effects in lexical decision and recognition. Journal of Experimental Psychology: General, 114, 435-450.

Salasoo, A., Shiffrin, R., \& Feustal, T. (1985). Building permanent memory codes: Codification and repetition effects in word identification. Journal of Experimental Psychology: General, 114, 50-77.

Scarborough, D., Cortese, C., Scarborough, H. (1977). Frequency and repetition effects in lexical memory. Joumal of Experimental Psychology: Human Perception \& Performance, 3, 1-17.

Schacter, D. L., Cooper, L. A., \& Delaney, S. M. (1990). Implicit memory for unfamiliar objects depends on access to structural descriptions. Journal of Experimental Psychology: General, 119, 5-24.

Squire, L., Shimamura, A., \& GRAF, P. (1987). Strength and duration of priming effects in normal subjects and amnesic patients. Neuropsychologia, 25, 195-210.

TogliA, M., \& BATTIG, W. (1978). Handbook of semantic word norms. Hillsdale, NJ: Erlbaum.

Tulving, E., \& Schacter, D. (1990). Priming and human memory systems. Science, 247, 301-306.

WiLDING, J. (1986). Joint effects of semantic priming and repetition in a lexical decision task: Implications for a model of lexical access Quarterly Journal of Experimental Psychology, 38A, 213-228.

\section{APPENDIX}

Words

$\begin{array}{llll}\text { BASIN } & \text { APPLE } & \text { BEACH } & \text { BLADE } \\ \text { BIBLE } & \text { BEARD } & \text { BLOOD } & \text { CHAIN } \\ \text { BRASS } & \text { BOOTH } & \text { BRUSH } & \text { CHOIR } \\ \text { CANDY } & \text { CABIN } & \text { CHALK } & \text { COUCH } \\ \text { CHINA } & \text { CHEST } & \text { COACH } & \text { DRESS } \\ \text { CORAL } & \text { COAST } & \text { CROWD } & \text { FLOOR } \\ \text { DAISY } & \text { CRUMB } & \text { DRINK } & \text { GRAPE } \\ \text { FLEET } & \text { FENCE } & \text { FROST } & \text { HORSE } \\ \text { GLOBE } & \text { FRUIT } & \text { GLASS } & \text { JUICE } \\ \text { HONEY } & \text { GUARD } & \text { HOUSE } & \text { LUNCH } \\ \text { JEWEL } & \text { JELLY } & \text { KNIFE } & \text { NIGHT } \\ \text { LINEN } & \text { LIGHT } & \text { MAPLE } & \text { PASTE } \\ \text { MOUSE } & \text { MEDAL } & \text { OLIVE } & \text { PLANE } \\ \text { PAPER } & \text { ORGAN } & \text { PATCH } & \text { QUILT } \\ \text { PENNY } & \text { PEARL } & \text { PLATE } & \text { SKIRT } \\ \text { QUEEN } & \text { PUPIL } & \text { RIFLE } & \text { STRAW } \\ \text { SKATE } & \text { SHEEP } & \text { SMOKE } & \text { TOAST } \\ \text { SPEAR } & \text { SOUND } & \text { SUGAR } & \text { UNCLE } \\ \text { TEETH } & \text { TABLE } & \text { TRAIL } & \text { WHEAT } \\ \text { TROUT } & \text { TROOP } & \text { WHEEL } & \text { WRECK }\end{array}$

Nonwords

$\begin{array}{llll}\text { ARNOR } & \text { ALREY } & \text { BOACH } & \text { BLACH } \\ \text { BRAIF } & \text { BORCH } & \text { BREAM } & \text { BRAME } \\ \text { CAGLE } & \text { BRULK } & \text { CEILD } & \text { CAMET } \\ \text { CILOR } & \text { CHAOR } & \text { CLOID } & \text { CROAL } \\ \text { CROOM } & \text { CROLN } & \text { CUBLE } & \text { CRUAM } \\ \text { DRULL } & \text { DATCH } & \text { FLOOP } & \text { EARSH } \\ \text { GANCE } & \text { FLOWL } & \text { GLESS } & \text { GLAVE } \\ \text { GREIN } & \text { GLODE } & \text { IVORA } & \text { HATEL } \\ \text { KIVER } & \text { KIGER } & \text { LIVET } & \text { MASIC } \\ \text { MAROR } & \text { MAGLE } & \text { MEACH } & \text { MOOTH } \\ \text { MODEY } & \text { MEART } & \text { MOUSH } & \text { NIVEL } \\ \text { NEMON } & \text { NAULT } & \text { NOBIN } & \text { PHODE } \\ \text { ONIOL } & \text { ODEAN } & \text { PIATO } & \text { PRAIN } \\ \text { PLUNT } & \text { PLOTH } & \text { PURSH } & \text { SERRY } \\ \text { QUARP } & \text { QUAID } & \text { SHILT } & \text { SMOLE } \\ \text { SLOOT } & \text { SLOVE } & \text { SNADE } & \text { SOTIN } \\ \text { SNELL } & \text { SNAVE } & \text { STEAF } & \text { SLICH } \\ \text { STENE } & \text { STEEK } & \text { THIEK } & \text { SWOLD } \\ \text { SWEAK } & \text { STOOK } & \text { WHIBE } & \text { WILCH } \\ \text { WETAR } & \text { TROBE } & \text { WODAN } & \text { LIGAR }\end{array}$

(Manuscript received August 17, 1989; revision accepted for publication May 14, 1990.) 